\title{
Adaptação transcultural de intervenções psicossociais na esquizofrenia
}

A família tem um lugar e uma função centrais na vida dos portadores de esquizofrenia. Essas pessoas freqüentemente vivem com a família de origem ou mantêm contato regular com familiares, o que significa que são esses que geralmente identificam inicialmente algum problema, buscam o tratamento, tornam-se responsáveis pela administração das prescrições médicas e articuladores do cotidiano de seu familiar doente. Nessa convivência, aprendem a enfrentar momentos de agravamento do quadro sintomatológico e a manejar situações de inatividade, depressão, agressividade, confusão, desorganização e inadequação. O cotidiano familiar é marcado por uma permanente imprevisibilidade e pelas questões: "Quando será a próxima crise?" ou “Quanto tempo vai durar essa fase boa?". Além disso, os familiares têm que redimensionar as expectativas quanto ao futuro de seu familiar doente e quanto ao próprio futuro face à demanda de cuidados que gera custos e perdas para todos. Também precisam auxiliar o doente a lidar com suas perdas e com o empobrecimento de sua vida social, afetiva e profissional. Tudo isso constitui a experiência do "fardo" ou sobrecarga familiar. ${ }^{1-3}$

Reconhecendo essa realidade, os profissionais e os planejadores de serviços de saúde concordam sobre a importância de se prover serviços aos familiares de portadores de esquizofrenia, mas vários fatores ainda contribuem para dificultar a implantação e a condução efetiva desses. Diversos autores $^{4-6}$ têm analisado as barreiras entre o sistema de saúde e as famílias de pacientes com esquizofrenia, uma vez que essas representam um problema que deve ser abordado para que se viabilize a oferta de serviços adequados às realidades socioculturais dessas famílias.

Riesser e Schorske ${ }^{4}$ apontam, por exemplo, como nos EUA o processo de desinstitucionalização do paciente psiquiátrico não foi adequadamente acompanhado do desenvolvimento de recursos comunitários suficientes, e como isso contribuiu para o aumento do fardo familiar ao separar, de maneira inapropriada, cuidado de tratamento: a família tornou-se cuidador e o sistema de saúde o responsável pelo tratamento, continuando a deter a autoridade quanto aos procedimentos e serviços oferecidos, sem integrar esses dois aspectos. Dixon ${ }^{6}$ cita o exemplo do Reino Unido, onde estudos sobre o padrão de resposta emocional dos familiares em relação ao familiar doente geraram a teoria das emoções expressas (EE) que, rapidamente, tornou-se um parâmetro para a avaliação das relações familiares nesses contextos. Segundo a autora, a maioria dos programas psicoeducacionais para familiares derivou, pelo menos em parte, da teoria das EE. Essas intervenções inicialmente enfatizavam a diminuição dos comportamentos e atitudes familiares "negativas" e, embora tenham posteriormente se ampliado, são em geral conduzidas por profissionais e possuem um enfoque mais clínico, enquanto os programas educacionais, desenvolvidos e conduzidos por leigos (grupos de familiares e amigos de portadores de transtornos mentais), são realizados na comunidade e se baseiam principalmente em teorias de redução de estresse, de desenvolvimento de recursos para lidar com a doença, da adaptação e de estratégias de apoio, ou seja, visam reforçar e desenvolver os recursos existentes, não enfocando primordialmente aspectos disfuncionais dos relacionamentos familiares. Esses dois modelos de abordagem familiar permanecem, ainda hoje, pouco integrados.

Um outro fator gerador de barreiras entre profissionais e familiares foi a importância das construções teóricas atribuindo a etiologia da esquizofrenia a aspectos relacionais entre pais e filhos (e particularmente à relação mãe-filho). Essas teorias também contribuíram para aumentar o fardo familiar, gerando mais estigma, e refletiram negativamente na clínica, colocando profissionais em posição de crítica e confronto com os familiares responsabilizados pela doença de seu familiar diagnosticado como esquizofrênico. Um dos resultados desse posicionamento foi o isolamento das famílias que, acuadas e pouco acolhidas pelos profissionais de saúde mental, iniciaram suas próprias organizações. As famílias norte-americanas, por exemplo, descobriram aos poucos o potencial dos grupos de auto-ajuda. Em 1979, a formação da Nami (National Alliance for the Mentally Ill) marcou o início de um movimento nacional que hoje congrega por volta de 150.000 membros em mais de mil afiliações locais e estaduais. Esses grupos promovem, entre outras atividades, encontros periódicos de familiares, no quais se trocam informações, experiências, discutem-se alternativas, constituindo espaços de aprendizado, de apoio e de formação de redes sociais de solidariedade. ${ }^{4}$

O movimento de advocacia familiar e as novas pesquisas, validando teorias neurobiológicas da vulnerabilidade constitucional nos transtornos esquizofrênicos, deram sustentação para a realização de numerosos trabalhos de investigação de aspectos ambientais e familiares, e guiaram o desenvolvimento de intervenções familiares psicossociais nas últimas décadas. Atualmente, dentre as recomendações para o cuidado de pessoas com esquizofrenia validadas em extensivos estudos e revisões 
de literatura, ${ }^{7}$ três referem-se especificamente à intervenção familiar psicossocial: (1) deve ser oferecida intervenção familiar por pelo menos nove meses, constando de combinações de informações sobre a doença, apoio familiar, intervenção nas crises e treinamento em resolução de problemas; (2) as intervenções não devem ser restritas às famílias identificadas como tendo altos níveis de EE; (3) não se deve empregar intervenções familiares baseadas na premissa de que uma disfunção familiar é a etiologia do transtorno.

É importante notar que essas recomendações não definem uma intervenção específica e não presumem que todas as famílias devam participar de alguma intervenção para que o tratamento seja mais efetivo.

Há, porém, muito a ser estudado no campo das abordagens familiares. Pouco se sabe ainda, por exemplo, sobre a abrangência dos serviços oferecidos: quais famílias têm se beneficiado? Que parcela do total de famílias é essa? O que querem os familiares? O que funciona melhor para quem e onde? Qual o custo desses serviços?

Uma outra questão intrigante é o fato da intervenção familiar ser ainda hoje um serviço muito limitado, apesar de sua comprovada efetividade. A falta de profissionais capacitados para esse tipo de intervenção é uma possível explicação - mas não a única - e essa deficiência deve estar relacionada também à histórica dificuldade de relacionamento entre profissionais e famílias. Outros fatores precisam ser analisados para que se coloquem em prática serviços mais abrangentes para as famílias. Uma importante estratégia nesse sentido será o desenvolvimento de modelos híbridos, somando, à experiência dos modelos administrados por profissionais, a dos desenvolvidos por leigos.

No Brasil, o processo de desinstitucionalização dos doentes mentais é recente. Falta a implementação de políticas de tratamento e de reabilitação, e faltam estudos para orientar e avaliar as novas formas de intervenção na comunidade. De maneira geral, a abordagem familiar nos serviços de tratamento é desenvolvida dentro de uma questão de bom senso. O profissional sabe que é preciso orientar os familiares a respeito das necessidades e do cuidado do doente, mas isso é feito sem que ele se pergunte, por exemplo: o que significa orientar uma família? O que eles precisam saber? Ou, ainda, o que eles querem saber? Mais raramente ainda, se coloca a questão: o que significa entender um problema? Como as pessoas constroem as explicações?
A partir dessas questões e da ausência de modelos adequadamente testados, profissionais do Proesq (Programa de Esquizofrenia do Departamento de Psiquiatria da Unifesp) criaram em 1997 um "Núcleo de família" com o objetivo de estudar, planejar e desenvolver um conjunto de abordagens familiares, buscando integrar dados da cultura local para orientar esse processo. A experiência do Proesq vem se estruturando a partir da análise da literatura sobre os modelos de intervenção familiar, ${ }^{8-10}$ de estudos de revisão sistemática, ${ }^{11-12}$ e de um estudo etnográfico realizado com familiares de pacientes do programa. ${ }^{13}$ Esse estudo possibilitou entender a articulação cultural da experiência da doença na dimensão da convivência familiar cotidiana. Ao focar a análise sobre o processo de construção do significado da doença e sobre os dilemas e as estratégias desenvolvidas pelas famílias para lidar com essa realidade, evidenciou-se, por exemplo, a importância de se entender a doença do ponto de vista das famílias e de se empreender uma aproximação entre as leituras leiga e profissional da doença e suas implicações para o tratamento. ${ }^{13-15}$

O Núcleo de Família vem desenvolvendo, desde 1998, um modelo de orientação familiar denominado "Seminários informativos sobre a esquizofrenia". ${ }^{16}$ Esse projeto visa promover um espaço educativo para os familiares, em que a informação e a orientação são construídas por um processo colaborativo entre familiares e profissionais. Os temas e as questões relevantes são selecionados por meio de discussões em grupo. Utilizam-se diversos recursos didáticos ao longo de 10 a 12 encontros, nos quais se trabalham informações e se compartilham experiências de alternativas para a convivência com a doença.

Embora não existam ainda dados conclusivos sobre esse projeto, todos os participantes reconhecem a importância de saber mais sobre a doença para lidar com as intercorrências dessa convivência; sua participação nos encontros tem contribuído para melhorar a adesão dos pacientes ao tratamento. Além disso, o projeto tem propiciado que as famílias reconheçam e validem a experiência e os recursos que já possuem, que constituam um grupo de apoio e formulem novas demandas. A "Comissão de familiares", um protótipo de organização de auto-ajuda e advocacia familiar, foi formada em consequiência desse trabalho. Outras propostas estão sendo encaminhadas. Percebe-se, inequivocamente, a importância de um diálogo mais simétrico entre profissionais e familiares e de um espaço não clínico para esses elaborarem suas experiências, formularem perguntas, trocarem e ampliarem conhecimentos.

\section{Referências}

1. Desjarlais R, Eisenberg L, Good B, Kleinman A. World mental health. New York: Oxford University Press; 1995.

2. Johnson DL. Current issues in family research: can the burden of mental illness be relieved? In: Lefley HP, Wasow M, editors. Helping families cope with mental illness. USA: Harwood Academic Publishers; 1994. p. 309-28.

3. Hartfield AB. Semantic barriers to family and professional collaboration. Schizophr Bull 1986;12:325-33.
4. Riesser GG, Schorske BJ. Relationships between family caregivers and mental health professionals: the american experience. In: Lefley HP, Wasow M, editors. Helping families cope with mental illness. USA: Harwood Academic Publishers; 1994. p. 3-26.

5. Wasow M. Professional and parental perspectives. In: Lefley HP, Wasow M, editors. Helping families cope with mental illness. USA: Harwood Academic Publishers; 1994. p. 27-38. 
6. Dixon L. Providing services to families of persons with schizophrenia: present and future. J Mental Health Policy Econ 1999;2:3-8.

7. Lehman AF, Steinwachs DM, Buchanan R, Carpenter, WT Dixon L, Fahey M, et al. At issue: translating research into practice: the Schizophrenia Patient Outcomes Research Team (PORT) treatment recommendations. Schizophr Bull 1998;24:1-9.

8. Anderson CM, Reiss DJ, Hogarty GE. Schizophrenia and the family. New York: The Guilford Press; 1986.

9. Marsh DT. Families and mental illness: new directions in professional practice. New York: Praeger; 1992.

10.Lefley HP, Wasow M, editors. Helping families cope with mental illness. USA: Harwood Academic Publishers; 1994.

11.Mari JJ. Intervenções familiares e recaídas na esquizofrenia: metanálise dos resultados de pesquisas [dissertação]. São Paulo: Escola Paulista de Medicina; 1995.
12.Mari JJ, Streiner D. An overview of family interventions and relapse on schizophrenia: meta-analysis of research findings. Psychol Med 1994:24:565-78.

13.Villares CC. Representações de doença por familiares de pacientes com diagnóstico de esquizofrenia [dissertação]. São Paulo: Universidade Federal de São Paulo; 1996.

14.Villares CC, Mari JJ. Esquizofrenia e contexto familiar. In: Shirakawa I, Chaves AC, Mari JJ, editors. O desafio da esquizofrenia. São Paulo: Lemos Editorial; 1998. p. 243-55.

15.Villares CC, Redko CP, Mari JJ. Concepções de doença por familiares de pacientes com diagnóstico de esquizofrenia. Rev Bras Psiquiatr 1999;21:36-47.

16.Villares CC, Natel MT, Ribeiro IB. Conversando com familiares sobre a esquizofrenia. Psychiatry on Line [serial online]1999b; 4(4). Available from: URL: http://www.polbr.med.br/esq0599.html

Correspondência: Cecília Cruz Villares

Departamento de Psiquiatria da Unifesp - Rua Botucatu, 740, $3^{\circ}$ andar, Vila Clementino CEP 04023-000 São Paulo, SP - E-mail: cvillares@ psiquiatria.epm.br 